\title{
O OLHAR COMO EXPERIÊNCIA ALIENANTE
}

\section{Luciene Braga Ramos Borges ${ }^{1}$; Malcom Guimarães Rodrigues ${ }^{2}$}

1. Bolsista PIBIC/CNPq, Graduanda em Licenciatura em Filosofia, Universidade Estadual de Feira de Santana, e-mail: luci eneramos@hotmail.com 2. Orientador: Dr. Malcom Guimarães Rodrigues, Departamento de Ciências Humanas e Filosofia, Universidade Estadual de Feira de Santana, e-mail: malcomgr@gmail.com

PALAVRAS-CHAVE: Para-Si; Para-Outro; Sartre

\section{INTRODUÇÃO}

Jean-Paul Sartre, descreve na obra O Ser e o Nada (1943/2014), sobre uma concepção filosófica a partir do que ele defende como existencialismo. O existencialismo parte da premissa de que: "a existência precede a essência" (2014, p.695), em contraposição ao pensamento vigente que se sustenta na premissa contrária "a essência precede a existência". ${ }^{1} \mathrm{O}$ autor afirma que a premissa, acima citada, é o primeiro princípio do existencialismo e descreve, a partir daí, a realidade humana como "fazendo-se", liberdade plenamente responsável por suas ações no mundo concreto. Inclusive, Sartre apresenta-se como um exemplo da sua filosofia, ao fazer-se um autor engajado nas situações importantes da sua época. Existiu como uma realidade humana vivendo intensamente cada momento histórico e sustentou as afirmações contidas em seus textos e obras quando a questão era agir sendo esta liberdade. No que concerne ao tema proposto, "O Olhar como alienante", Sartre descreve, a partir da questão da existência do Outro, na obra O Ser e o Nada (1943/2014), na qual ele explica que uma das modalidades em que o Outro aparece, para a realidade humana, é através de uma relação de objetividade, como uma das modalidades da presença do Outro a mim: O Olhar do outro dirigido a mim que faz com que eu perca a subjetividade e me experiencie como objeto. Esta é uma experiência alienante que eu, como realidade humana, procuro evitar. O ponto de partida para se chegar a questão do olhar, como alienante, é entendermos como o Outro aparece para a realidade humana, na perspectiva de Sartre.

\section{MATERIAL E MÉTODOS OU METODOLOGIA (ou equivalente)}

A natureza desta pesquisa é bibliográfica, os materiais usados são de ordem textual: livros, artigos, textos etc. A metodologia consiste em: leituras, fichamentos, análises textuais das obras propostas, relacionadas ao tema, citadas nas referências. Os encontros com o orientador e a participação no grupo de estudos foram fundamentais. Em um primeiro momento da pesquisa, abordamos as críticas apontadas, por Sartre, na obra $O$ Ser e o Nada (1943/2014), referentes aos autores que também debruçaram-se sobre a questão da existência do Outro e que, segundo ele, contribuíram para o debate. Em seguida, nos voltamos para a relação entre o idealismo, o realismo e a questão do Solipsismo. Por último, analisamos o conceito do Olhar, como experiência alienante e que buscamos evitar, tentando estabelecer os três tipos de relação que Sartre aponta na obra: o Outro como objeto do qual me aproprio; o Outro como aquele que assume uma perspectiva sobre os mesmos objetos para os quais estou olhando e o Outro como aquele que me olha, me objetifica e me aliena. Algumas notas de rodapé foram extraídas de pesquisas anteriores, levando em consideração que os temas das pesquisas são muito próximos. Utilizamos as que se fizeram necessárias para uma melhor compreensão do tema recortado: "O Olhar como experiência alienante".

\footnotetext{
1 Na obra Fenomenologia (2012) David R. Cerbone descreve sobre o termo existencialismo da seguinte forma: 'O termo “existencialismo' (na verdade, seu equivalente francês) foi cunhado por Marcel, que o aplicou ao pensamento de Sartre e de Simone de Beauvoir. Sartre, inicialmente, rejeitou a denominação, afirmando não saber o que significava. Logo depois, em o seu $O$ existencialismo é um humanismo Sartre aplicou providencialmente o termo, tanto à sua própria concepção, como e de outros antes dele [...]. Para Sartre os compromissos definidores do existencialismo são, em primeiro lugar, que no caso dos entes humanos, 'a existência precede a essência', e, em segundo, que 'a subjetividade deve ser o ponto de partida'. O que essas duas sentenças indicam é o interesse do existencialismo pelo caráter especial da existência humana, como algo irredutivelmente subjetivo e, portanto, inadequado para ser completamente apreciado ou explicado a partir de um ponto de vista objetivo". (CERBONE, 2012, p.134)
} 


\section{RESULTADOS E/OU DISCUSSÃO (ou Análise e discussão dos resultados)}

Jean-Paul Sartre afirma, na terceira parte da obra O Ser e o Nada (1943/2014), O Para-Outro, capítulo I - "A existência do Outro, o problema", que há uma estrutura ontológica radicalmente diferente da realidade humana como Consciência, porém uma estrutura que permanece sendo da realidade humana. ${ }^{2}$ É dela, mas sem ser para ela, posto que é um ser Para-Outro. É uma nova estrutura cujo surgimento está relacionado com a questão da existência do Outro. Para Sartre, segundo Bornheim, na obra Sartre - Metafísica e existencialismo (1984), a realidade humana, em seu próprio ser, é "congenitamente Para-Si-Para-Outro" (BORNHEIM, 2010, p.80). O Outro, a princípio mostra para a realidade humana uma estrutura até então desconhecida para ela mesma, o ParaOutro. Um novo modo de ser que sustenta novas qualificações. No entanto, esta estrutura a realidade humana é de forma "originária e constitutivamente" (BORNHEIM, 1984, p.82). ${ }^{3}$ Quando o Outro aparece para a realidade humana é, portanto, na condição de mediador entre ela e ela mesma, o que a torna capacitada para formular juízos sobre si mesma assim como ela formula juízos sobre um objeto qualquer. Neste sentido, é na condição de objeto que a realidade humana aparece para o Outro. No entanto, é importante observar que o que aparece para o Outro, nestas circunstâncias, não é uma imagem na mente dele (representação/idealismo) mas um reconhecimento da própria realidade humana, naquilo que ela é, para o Outro, no exato instante em que o Outro a vê. Por exemplo: na vergonha o ser que a vergonha revela, a realidade humana é este ser. Ela é a vergonha no modo de ser do Em-Si, não como imagem ou representação, mas como uma dimensão de ser que depende do encontro com o Outro. É através da experiência cotidiana que ela descobre a realidade do Outro. A perspectiva sartreana aponta o encontro com o Outro como imprescindível para que possamos apreender esta nova estrutura da realidade humana dentro do mundo, ou seja, no encontro, o Outro é aquele que vemos e ao mesmo tempo aquele que nos vê. Então, quando o Outro aparece para a realidade humana, concretamente, a constitui em um novo Ser que não se encontra nela como potência antes que ela seja para o Outro, mas também não está no Outro, pois para Sartre (2014, p. 290), a realidade humana é responsável por este Ser ou esta estrutura - o Para-Outro. O que Sartre (2104, p.295) observa, é que a realidade humana e o Outro são duas consciências humanas distintas, não existe relação entre uma consciência e outra consciência, da forma como querem os idealistas nas suas suposições, ou seja, o Outro não é esse que serve para unificar os fenômenos da nossa experiência, mas certas categorias de fenômenos existem somente para ele. Sendo assim, o conceito do Outro não pode constituir uma experiência da realidade humana. Em certo sentido, o Outro é uma negação da minha experiência como sujeito pois, não é somente aquele que vejo, mas também aquele que me vê, me objetifica e me aliena. Na obra $O$ Ser $e$ o Nada (1943/2014), Sartre parece apontar para a não possibilidade de um reconhecimento mútuo entre duas consciências, quando descreve os modos de relacionamento entre uma realidade humana e outra realidade humana. $\mathrm{O}$ fato de que, ao sermos olhados ou quando olhamos o Outro, isto não signifique apenas que olhos nos veem, mas que somos convertidos ora em objeto ora em sujeito já aponta para uma relação de não reciprocidade e, portanto, de conflito. O que a alienação e a objetificação implicam para além desta não reciprocidade? Algo mais complexo, como apontam as criticas as quais Sartre $(2010, \mathrm{p} .20)$ focou em responder na Conferência $O$ Existencialismo é um humanismo (1946/2010): pensar o homem entendido como "um ser isolado" porque partindo do eu penso cartesiano, como pura subjetividade, este homem estaria consigo mesmo em sua solidão, o que o tornaria incapaz de pensar no outro, já que o Outro estaria fora de si (do homem) e não seria atingido no cogito. Para Sartre (2014, p. 316), o verdadeiro terreno onde se inscreve a existência do Outro é fazendo com que este participe da certeza apodítica do cogito, onde cada consciência encontra, na interioridade do cogito, o ser do Outro como uma transcendência. ${ }^{4}$ Sartre $(2010$, p.47), apesar de ter sido alvo de muitas críticas, em relação a

\footnotetext{
${ }^{2}$ A consciência, para Sartre, é entendida como pura espontaneidade, "nasce" contemporaneamente com o mundo e "[...] com efeito, a consciência se define pela intencionalidade" (SARTRE, 2013, p. 21), essa necessidade que ela tem de existir como consciência de outra coisa que não é ela, tese que é afirmada na obra $A$ transcendência do Ego (1934/2013), reforçada na obra O Ser e o Nada (1943/2014a) e defendida na conferência O Existencialismo é um Humanismo (1946/2010).

${ }^{3}$ Uma estrutura diferente da relação da realidade humana (Para-si) com o mundo (Em-si), na qual o Para-si é, como afirma Sartre (2014, p. 236) é “[...] os ser para o qual, em seu próprio ser, está em questão o seu ser, enquanto este ser é essencialmente um certo modo de não ser um ser que, ao mesmo tempo, ele posiciona como outro que não si mesmo". (SARTRE, 2014, p. 234). Esta uma estrutura da própria realidade humana.

${ }^{4} \mathrm{Na}$ conferência $O$ existencialismo é um humanismo (2010), Sartre afirma acerca do cogito: “ [...] demonstramos que no cogito não se revelava apenas a si mesmo, mas também aos outros. Pelo eu penso, contrariamente à filosofia de Descartes, e contrariamente à
} 
forma de pensar a realidade humana centrada nos projetos de si mesma, sem possibilidades de um encontro intersubjetivo com o Outro, afirma que não se pode pensar a realidade humana de forma isolada. Neste sentido, ela, sendo aquela que faz com que haja um mundo, também é responsável pelo mundo inteiro. Então, diante disto, devemos pensá-la sempre em relação com o mundo e com o Outro, mesmo que esta relação seja conflituosa. A realidade humana, entendida como perpétuo jogo de evasão entre Para-si e Para-outro, afinal esta é uma estrutura da qual não poderá afastar-se, pois como Para-si-Para-outro, nas palavras de Sartre (2014, p. 352), ela cai através do vazio absoluto em direção à objetividade. Ser objeto para o Outro, ou seja, uma queda que ao mesmo tempo é alienação. Uma alienação que começa com o olhar do Outro sobre ela.

\section{CONSIDERAÇÕES FINAIS (ou Conclusão)}

O que significa o Olhar do Outro como experiência alienante? ${ }^{5}$ O Olhar do Outro é uma remissão a mim, "[...] um intermediário que me remete de mim a mim mesmo" (SARTRE, 2014, p. 334). Quando o Outro me olha e eu percebo acontecem modificações essenciais nas minhas estruturas. Eu posso, a partir daí, captar-me enquanto eu para minha consciência irrefletida. ${ }^{6}$ Este eu, a título de objeto, só se revelaria, a princípio, a uma consciência reflexiva, portanto, neste aspecto, a consciência irrefletida não capta o eu de forma direta, mas indireta, ou seja, o eu está presente à consciência enquanto é objeto para o Outro. Neste aspecto, ao me olhar o Outro está presente a mim, porém, não como imagem, nem tão pouco o conheço. Ele se revela a mim como vivência, vivo a situação de Ser-Visto. Então, o Olhar do Outro me lança além do meu universo em uma fuga que não tem limites. Eu capto este Olhar como uma solidificação de mim mesmo, como se eu adquirisse uma natureza, um lado de fora, onde fico despojado da minha transcendência, alienado das minhas possibilidades. ${ }^{7}$ Eu vivo isto no meio do mundo, pois segundo Sartre (2014, p. 346), o Outro aparece para a realidade humana por encontro, como foi dito acima, e quando aparece esta não é mais dona da situação, encontra-se "temporariamente" objetivada,

Assim, no brusco abalo que me agita quando capto o olhar do Outro, ocorre que, de súbito vivo uma alienação sutil de todas as minhas possibilidades, que se arrumam longe de mim, no meio do mundo, com os objetos do mundo. (SARTRE, 2014, p. 341)

O Ser-Visto pelo Outro modifica as estruturas da realidade humana e, neste sentido ela fica alienada, ela escapa de si mesma e o seu fundamento é fora, no Outro, porque a realidade humana reconhece o Outro como uma consciência igual a ela, livre e capaz de transcender a sua transcendência. É pelo olhar do Outro, sobre si, que a realidade humana vive a alienação das suas possibilidades e já não é mais dona da situação, encontra-se em perigo no mundo. Para Sartre (2014, p.645), não podemos escapar a experiência da alienação, advinda do olhar do Outro, pois seria absurdo sequer sonhar em existir de outro modo que não em situação. A aparição do Outro, no mundo da realidade humana, é a descentralização do seu universo e, a relação ser-visto-pelo-outro é a possibilidade permanente para um sujeito (Outro), que vê a realidade humana, substituir o objeto (Outro) visto por ela, portanto, para Sartre, na obra $O$ Ser e o Nada (1943/2014), a relação vai ser sempre conflituosa. A

filosofia de Kant, nós estamos nos apreendendo a nós mesmos diante do outro, e o outro é algo tão certo para nós quanto o somos nós mesmos. Assim, aquele que se apreende de maneira imediata pelo cogito, descobre também todos os outros, e os descobre como a condição de sua própria existência. Ele se apercebe que não pode ser nada (no sentido em que dizemos que somos espirituais, ou maus ou ciumentos), a não ser que os outros o reconheçam como tal". (SARTRE, 2010, p.47)

${ }^{5}$ É necessário, segundo Sartre (2014. p. 333) algumas observações importantes em relação ao Olhar: 1) não é uma qualidade do olho; 2) se apreendo o olhar, deixo de perceber os olhos; 3) os olhos estão fora de circuito; 4) o Olhar do Outro disfarça seus olhos,adiantando-se a eles; 5) ao olhar o Olhar do Outro minha percepção se decompõe e passa a segundo plano; 6) captar um Olhar do Outro é tomar consciência de ser visto. Cf. Sartre, 2014, p.333

${ }^{6} \mathrm{Na}$ obra $A$ transcendência do ego (1934/2013), Sartre denomina a consciência de primeiro grau como irrefletida, posteriormente, na obra O Ser e o Nada (1943/2014a), ele passa a denominar a mesma consciência de primeiro grau como cógito pré-reflexivo. Trata-se, portanto, da mesma consciência entendida como anterior a reflexão.

7 Maria José Neto Andrade, no artigo “A Liberdade como fundamento de uma ética sartreana" (2004) explica que a dimensão alienadora, para Sartre, é existir como forma em-si para o Outro. Ela não pode ser removida pela Realidade Humana, e não pode sofrer a sua ação direta: "Desse modo, a alienação consiste na exterioridade da própria situação que representa seu ser-fora-para-o-outro, isto é, refere-se a uma dimensão do indivíduo que foge ao seu domínio, pois trata do que se revela ao outro como seu exterior. Na experiência da alienação há o reconhecimento do Outro como Liberdade" (ANDRADE, 2004, p. 237) 
realidade humana fica diante do Outro como Outro-objeto, mas não pode ser dispensada da sua condição de sujeito. Ela reconhece o Outro como sujeito, embora fora de alcance, reconhece-o como uma transcendência transcendida, no mundo concreto, onde ela está comprometida rumo a fins. O Outro se perde no mundo que é dela, pois existe em situação. Quem é sujeito e objetifica, quem é objeto, reage e objetiva o Outro vai depender da forma como está organizado o mundo e do encontro.

\section{REFERÊNCIAS}

SARTRE, J-P. O Ser e o Nada. Petrópolis: ed. Vozes, 2014.

\section{Demais referências}

ANDRADE, M. J. “A Liberdade como fundamento de uma ética sartreana". In; José Maurício de Carvalho. (org.) Problemas e teorias da ética contemporânea. $1^{\mathrm{a}}$ ed. Porto Alegre: EDIPUCRS, 2004, v., 221-252.

BORNHEIM, Gerd. A. Sartre - Metafísica e existencialismo. Editora Perspectiva. $2^{a}$ edição, São Paulo, 1984. (Coleção Debates)

CAYGILL, Howard. Dicionário Kant. Tradução Álvaro Cabral; revisão técnica, Valério Rohden. - Rio de Janeiro: Jorge Zahar Ed., 2000.

CERBONE, David R. Fenomenologia. Tradução: Caezar Souza. Petrópolis, RJ: Vozes, 2012.

COX, G. Compreender Sartre. Tradução de Hélio Magri Filho. - Petrópolis: RJ: Vozes, 2007.

COHEN-SOLAL, Annie. Sartre. 1905-1980. Paris. Gallimard, 1999.

KANT, Immanuel. Crítica da razão pura. Tradução e notas de Fernando Costa Matos - Petrópolis, RJ: Vozes; Bragança Paulista, 2012.

LÈVY, Bernard-Henri. O século de Sartre: inquérito filosófico. Rio de Janeiro: Nova Fronteira, 2001.

LEOPOLDO \& SILVA, F. O outro. São Paulo: Editora WMF. Martins Fontes, 2012.

MÉSZÁROS, István. A obra de Sartre: busca da liberdade e desafio da História. São Paulo: Boitempo, 2012.

REYNOLDS, Jack. Existencialismo. Tradução de Caesar Souza. - Petrópolis, RJ: Vozes, 2013. - (Série Pensamento Moderno).

RODRIGUES, Malcom Guimarães. Consciência e má-fé no jovem Sartre: a trajetória dos conceitos. - São Paulo: Ed. UNESP, 2010.

SARTRE, J-P A transcendência do ego. Lisboa: Edições Colibri, 1994. . Esboço de uma Teoria das Emoções. Rio de Janeiro: Jorge Zahar Ed., 1965.

. O imaginário São Paulo: Ática, 1996.

. O existencialismo é um humanismo. São Paulo: Abril Cultural, 1973. Coleção "Os pensadores".

. O que é a Literatura? Petrópolis, RJ: Vozes, 2015.

O que é a subjetividade? - 1. Ed. - Rio de Janeiro: Nova Fronteira, 2015.

As Palavras. Tradução de J. Guinsburg. 2.ed. Rio de Janeiro: Nova Fronteira, 2005.

. Situações I. Tradução de Rui Mário Gonçalves - Publicações Europa-América, (1947).

. "Entre quatro paredes. Peça em um ato". Tradução e notas de Guilherme de Almeida. Editor Victor Civita.

Abril S.A. Cultural Industrial, São Paulo, 1ª edição - março de 1977 